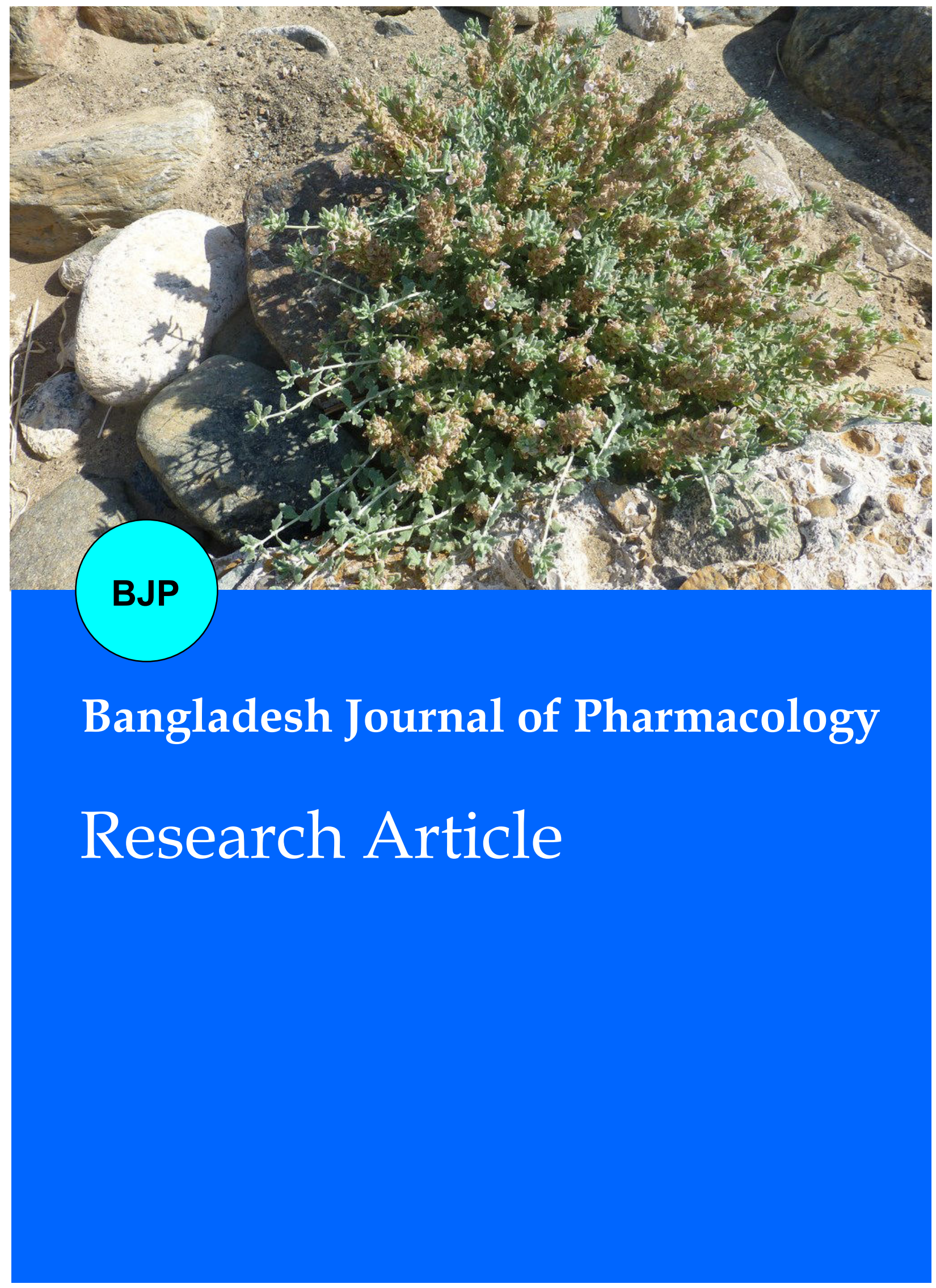


Abstracted/indexed in Academic Search Complete, Agroforestry Abstracts, Asia Journals Online, Bangladesh Journals Online, Biological Abstracts, BIOSIS Previews, CAB Abstracts, Current Abstracts, EMBASE/Excerpta Medica, Google Scholar, HINARI (WHO), International Pharmaceutical Abstracts, Open J-gate, Science Citation Index Expanded, SCOPUS and Social Sciences Citation Index;

\title{
Evaluation of pharmacological effect of Teucrium stocksianum extract on angiogenesis using chorioallantoic membrane assay
}

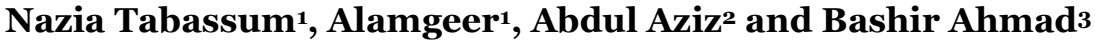 \\ ${ }^{1}$ Department of Pharmacy, University of Sargodha, Sargodha Pakistan; ${ }^{2}$ Department of Pharmacy, Bahauddin \\ Zakariya University, Multan, Pakistan; ${ }^{3}$ University College of Pharmacy, University of the Punjab, Lahore. Pakistan.
}

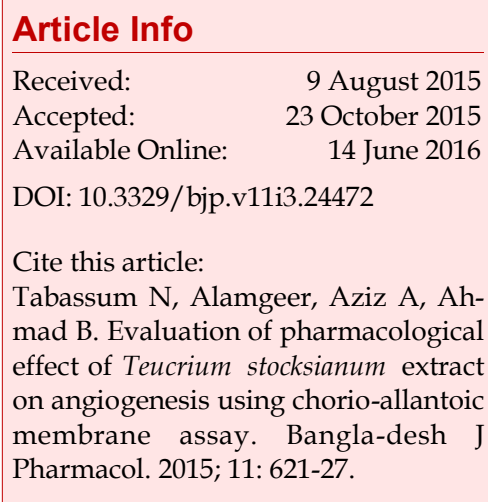

\section{Abstract}

The present study was aimed to evaluate the effect of Teucrium stocksianum on angiogenesis by using chorioallantoic membrane (CAM) assay. Fertilized eggs were incubated on the $5^{\text {th }}$ day and dose of different dilutions $0.03 \%$, $0.05 \%, 0.1 \%$, and $0.5 \%$ of the plant extract was applied on $6^{\text {th }}$ day. Evaluation of primary, secondary and tertiary blood vessels diameter and CAM area on 7th day by SPIP software. T. stocksianum showed anti-angiogenic effect by reducing the diameter of CAM of blood vessels by applying the dilutions while significant results were obtained at dilution of $0.5 \%$.

\section{Introduction}

Tumor cells development can be restrained by angiogenesis inhibition. Judah Folkman suggested first time that anti-angiogenesis was used as a target to treat tumor and reduce metastasis (Folkman, 1971). Many in vitro (endothelial cells migration assay, endothelial cells proliferation assay and tube formation assay) and in vivo [corneal angiogenesis assay and chorioallantoic membrane (CAM) assay] methods are adapted to assess anti-angiogenic and pro-angiogenic potentials of molecules (Auerbach et al., 2003).

Vascular endothelial growth factor (VEGF) and angiogenic factors IL production are accelerated with production of free radicals in cells (Brown et al., 2000). VEGF is a vital angiogenesis mediator which increases the expression of eNOS resulting VEGF-induced angiogenesis (Bouloumie et al., 1999). After binding on VEGF receptors promotes cellular events like migration, endothelial proliferation and extracellular matrix component (ECM) degradation (Ferrara and Davis-Smyth, 1997). Oxidative stress causes MMP-1 secretion resulting in tumor growth due to angiogenesis (Brown et al., 2000).
De novo development blood vessels perform vital role in tumor (Pepper, 1997).

Teucrium genus belongs to Lamiaceae family, having 300 species (Miller and Moris, 2004), grow in the Northern Oman, UAE (Western 1989; Nadaf et al., 2003) and Iran (Mojab et al 2003). Several effects were reported such as antioxidant, antinociceptive (Shah et al., 2014), skin disorders, antispasmodic (Ali and Shah, 2011), gastroprotective (Islam et al., 2002), burning feet syndrome, diabetes (Barkatullahet al., 2009; Alamgeer, et al., 2013), pyrexia (Naghibi et al., 2005), hepatoprotective activity (Rasheed et al, 1995), anthelmintic and cytotoxic (Ali et al., 2011).

The aim of study was to evaluate anti-angiogenic effect of different dilutions of Teucrium stocksianum using in vivo CAM assay.

\section{Materials and Methods}

\section{Chemicals used}

Methanol (analytical grade), ethanol, formaldehyde 
were purchased from BDH Laboratory Supplies, England. Buffered solution of $0.9 \%$ sodium hydroxide was purchased from E-Merck.

\section{Preparation of CAM}

Fifty fresh fertilized chicken eggs of $4^{\text {th }}$ day were obtained from a local hatchery (big bird). All the eggs were sprayed with $70 \%$ ethanol to reduce contamination from eggs surface and were air dried. Then eggs were incubated at $37^{\circ} \mathrm{C}$ at humidity $60-70 \%$ for 5 days (Lin et al., 2008). Eggs were divided into two groups. One was control and second was treated group. Treated group was further divided into 1, 2, 3 and 4 sub-groups. Ten eggs per group were taken. Then CAM assay was performed in the laminar flow hood on each chicken egg one by one. On day 5 of incubation, eggs were windowed aseptically (Ejaz et al., 2005). Briefly, a small window (approximately $2 \mathrm{~cm}$ in diameter) was made by removing the shell and inner shell membrane from the air-space site. On the same day, $4-5 \mathrm{~mL}$ of albumin was aspirated with a sterile syringe to allow the embryos to develop in a way accessible to quantification and enhance its manipulating properties and let the embryo to grow in a way easy for assessment. The windows were then sealed with sterile parafilm and eggs were returned to the incubator at $37^{\circ} \mathrm{C}$ (humidity $55-60 \%$ ) till day 6 of incubation.

\section{Plant material}

The aerial parts T. stocksianum were collected from hills of Talash District Dir (Lower), Malakand Division KPK (Pakistan), in the month of April 2011. The plant was identified and authenticated by the taxonomist Prof. Jehandar Shah, Vice Chancellor of Shaheed Benazir Bhutto University, Sheringle Dir (Upper).

\section{Preparation of extracts}

Aqueous methanolic (70:30) extract of T. stocksianum was prepared by using the cold maceration process. The grounded plant material $(3 \mathrm{~kg})$ was soaked in 7 liters of an aqueous methanolic mixture (70:30) for 72 hours at room temperature. After three days of occasional shaking, whole material was filtered and the solvent was evaporated under reduced pressure using rotary evaporator. The crude extract was then air-dried to obtain a solid mass.

\section{Samples administration}

On sixth day of incubation, windows of eggs of each group were opened and $150 \mu \mathrm{L}$ of dilution was applied on treated developing CAMs. Windows were sealed again with sterile parafilm and chicken eggs were returned to the incubator for 24 hours. On $7^{\text {th }}$ day, windows were opened and pattern of CAMs and CAMs area were evaluated by taking images with digital Lebecca cam at 30 frames/sec using a camera shutter speed of 1/2000 sec. Scanning probe image processor (SPIP) was used for quantification of results. All images were converted into grayscale for improved the contrast by black and white inversion with the help of Adobe Photoshop 6.0 so that every image possible to discern anatomical structures and to facilitate precise quantification of angiogenesis.

\section{Image acquision and quantification using SPIP soft- ware}

After the image acquisition, SPIP (IBM, Denmark) was used to evaluate the images which work on the specific algorithm (Garnaes et al., 2006). The length and diameter of different blood vessels were measured through the calibration and measurement command. The CAMs surface angiogenesis was precisely quantified by measuring the 3D surface roughness (14 parameters) which is an important parameter in the 3D image analysis. Vascular area, angular spectrum and abbot curve of CAMs were measured. The blood vessels were quantified in micrometer scale to evaluate the in depth effects of $T$. stocksianum extract on angiogenesis.

The essential parameters of 3D surface roughness are following: arithmetic average roughness (Sa) is the mean of absolute values of roughness profile. It is region between mean line and its roughness profile. This is simple and efficient parameter which facilitates us to describe the surface roughness. It can also be defined as the average height of analyzed area.

Four parameters are utilized to describe the surface amplitude. They are categorized into four groups i.e., a) extreme, b) dispersion, c) height distribution sharpness and d) asymmetry of the height distribution. The Sq is root mean square value of surface within sampling area. It is dispersion parameter.

Skewness of topography height distribution (Ssk) is the measure of asymmetry of surface deviations about the mean plane. It can be successfully used to illustrate the shape of topography height distribution. For a Gaussian surface which has symmetrical shape for surface height distribution, the skewness is zero. For an asymmetric distribution of surface heights, the skewness may be negative, if distribution has longer tail at lower side of mean plane or positive, if distribution has longer tail at upper side of mean plane. It can give some indication of existence of spiky features.

By combination of Sku and Ssk values, it can be achievable to identify surfaces having relatively flat, top and deep valleys.

Hybrid properties are combination of spacing and amplitude. Modification in either spacing or amplitude can modify the hybrid property. Two Hybrid parameters are measured in this study. Arithmetic mean summit curvature of surface (Ssc) is the average of the principal curvatures of summit within the sampling area. Whereas, the sum of curvatures of surface at point are equal to the sum of principal curvatures. 
Developed interfacial area ratio (Sdr) is the ratio of the increment of the interfacial area of surface over the sampling area. It reveals the hybrid surface property. The larger the Sdr value signifies the importance of either amplitude or spacing or both.

The functional parameters was observed in this study is core fluid retention (Sci). Core fluid retention index is the ratio of void volume of unit sampling area at the core zone over the root mean square deviation.

Maximum peak-to-valley roughness (Sy) is the vertical distance between the top of highest peak and bottom of deepest valley within sampling length. It is the maximum of all the peak-to-valley values.

\section{Statistical analysis}

All data was presented as mean \pm SD. Analysis of variance (ANOVA) was performed to evaluate different parameters between controlled and treated samples; statistical significance was set at $p<0.05$.

\section{Results}

\section{Photochemical analysis}

Preliminary study showed the presence of alkaloids, anthraquinone glycosides, saponins, cardiac glycosides, flavonoids, sterols, carbohydrates, amino acids and proteins.

\section{Effect on angiogenesis}

Blood vessels at macroscopic level

Anti-angiogenic activity was observed on application of T. stocksianum dilutions $(0.03 \%, 0.05 \%, 0.1 \%$ and $0.5 \%)$. They caused thinning of primary blood vessels (PBVs), secondary blood vessels (SBVs) and disappearing of tertiary blood vessels (TBVs) and reduced CAM area (Figure 1; Table I).

Diameter of blood vessels

The diameters of PBVs, SBVs and TBVs of treated groups $(0.03 \%, 0.05 \%, 0.1 \%$ and $0.5 \%)$ and control were measured by using the SPIP. The pronounced effect was seen at $0.5 \%$ (Figure 2 ).

\section{$3 D$ surface roughness of blood vessels}

The parameters of control CAM vasculature were greater than the treated CAMs vasculature parameters (Figure 1).

The Sa value of control was $81.1 \pm 1.0$. In T. stocksianumtreated groups, Sa was $72.3 \pm 2.2$ with $0.03 \%, 67.8 \pm 2.0$ with $0.05 \%, 49.2 \pm 2.5$ with $0.1 \%$ and $57.0 \pm 9.1$ with $0.5 \%$ respectively (Table II).

The Sq value of control was $86.1 \pm 3$ and in $T$. stocksianum-treated groups, Sq was $71.1 \pm 4.0$ with $0.03 \%, 71.5 \pm 1.6$ with $0.05 \%, 56.7 \pm 3.0$ with $0.1 \%, 64.8 \pm$
10.2 with $0.5 \%$ respectively (Table II). The Ssk value of control was $1.0 \pm 0.1$ and in treated groups it was $0.5 \pm$ 0.2 with $0.03 \%, 0.8 \pm 0.01$ with $0.05 \%, 0.1 \pm 0.0$ with $0.1 \%$ and $0.8 \pm 0.1$ with $0.5 \%$ respectively.

The Sku value of control was $2.3 \pm 0.0$ and in treated groups Sku was $3.3 \pm 0.1$ with $0.03 \%, 3.1 \pm 0.1$ with $0.05 \%, 3.6 \pm 0.1$ with $0.1 \%$ and $3.7 \pm 0.6$ with $0.5 \%$ respectively.

Ten point height of the surface is the mean of absolute heights of five highest peaks and the depths of five deepest pits or valleys of sampling area. It is extreme parameter. The $\mathrm{Sz}$ value of control was $282.5 \pm 2.2$ and in treated groups of T. stocksianum, $\mathrm{Sz}$ was $264.0 \pm 7.2$ with $0.03 \%, 261.0 \pm 1$ with $0.05 \%, 231.0 \pm 1.5$ with $0.1 \%$, $225.0 \pm 10.1$ with $0.5 \%$ for T. stocksianum (Table II).

The Ssc value of control was $1.9 \pm 1.1$ and in treated groups of T. stocksianum, Ssc was $1.0 \pm 2.6$ with $0.03 \%$, $1.0 \pm 6.0$ with $0.05 \%, 1.1 \pm 6.4$ with $0.1 \%$ and $1.3 \pm 2.0$ with $0.5 \%$ respectively. The Sdr value of control was 7.0 \pm 9.2 and in treated groups of T. stocksianum $\mathrm{Sdr}$ was 5.7 \pm 5.6 with $0.03 \%, 1.0 \pm 8.5$ with $0.05 \%, 4.2 \pm 5.2$ with $0.1 \%$ and $5.5 \pm 1$ with $0.5 \%$ respectively.

The Sci value of control was $1.9 \pm 0.1$ and in treated groups of T. stocksianum Sci was1.2 \pm 0.1 with $0.03 \%, 1.2$ \pm 0.1 with $0.05 \%, 1.1 \pm 0.0$ with $0.1 \%$ and $5.7 \pm 5.6$ with $0.5 \%$, (Table II).

The Sy value of control was $282.4 \pm 2.2$ and in treated groups of T. stocksianum Sy was $263.9 \pm 7.2$ with $0.03 \%$, $261.0 \pm 1$ with $0.05 \%, 231.0 \pm 1.5$ with $0.1 \%$ and $225.0 \pm$ 10.1 with $0.5 \%$ (Table II). The Sdq (root mean square slope) value of control was $0.000191 \pm 7.69 \mathrm{E}-06$ and in treated groups Sdq was $1.0 \pm 1.3$ with $0.03 \%, 1.0 \pm 5.1$ with $0.05 \%, 9.3 \pm 6.4$ with $0.1 \%, 8.7 \pm 6.6$ with $0.5 \%$ respectively.

The Spk (reduced summit height) value of control was $266.14 \pm 1.24$ and in treated groups, Spk was $249.1 \pm 3.1$ with $0.03 \%, 248.1 \pm 1.5$ with $0.05 \%, 160.3 \pm 1$ with $0.1 \%$ and $174.2 \pm 6.7$ with $0.5 \%$ respectively. The Stdi (texture index) value of control was $0.8 \pm 0.1$ and in treated groups Stdi $0.3 \pm 0.0$ with $0.03 \%, 0.5 \pm 0.1$ with $0.05 \%$, $0.5 \pm 0.077$ with $0.1 \%$ and $0.5 \pm 0.1$ with $0.5 \%$ respectively. The Sk (core roughness depth) value of control was $42.6 \pm 1.6$ and in treated groups of $T$. stocksianum, Sk was $29.6 \pm 2.1$ with $0.03 \%, 30.2 \pm 5$ with $0.05 \%, 32.0 \pm 3.0$ with $0.1 \%$ and $32.5 \pm 1.1$ with $0.5 \%$ (Table II). The Svk (reduce valley depth) value of control was $1.8 \pm 0.0$ and in treated groups of $T$. stocksianum, i was $1.3 \pm 0.1$ with $0.03 \%, 1.2 \pm 0.1$ with $0.05 \%, 1.3 \pm 0.1$ with $0.1 \%, 1.1 \pm 0.1$ with $0.5 \%$ respectively.

According to the 3D surface roughness parameters, heights and pits were less in the treated CAMs as compared to control CAMs because of less developed blood vessels. Similarly, other parameters such as root mean square slope, arithmetic mean summits, reduced 


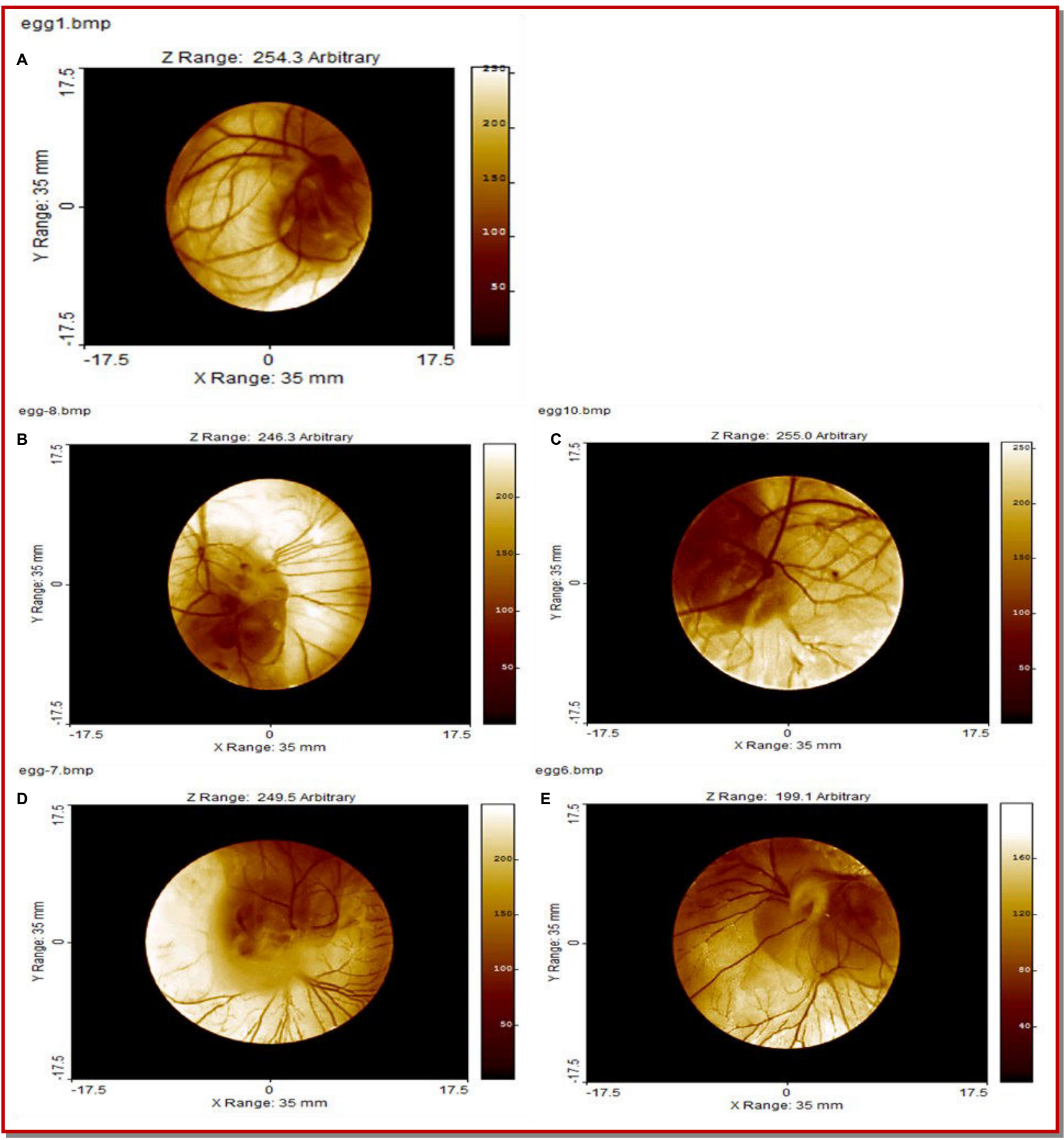

Figure 1: Macroscopic evaluation of chicken CAM. Well-defined vascular architecture of CAM vessels i.e. PBVs, SBVs, TBVs and well develop CAM area in (A) control while extensive deterioration of CAM vessels and reduction in CAM area representing anti-angiogenic activities in treated dilutions of T. stocksianum i.e. (B) $0.03 \%$ (C) $0.05 \%$ (D) $0.1 \%$ (E) $0.5 \%$

\begin{tabular}{|lccccc|}
\hline \multicolumn{5}{c|}{ Table I } \\
\hline Blood vessels & \multicolumn{5}{c|}{ Diameters of blood vessels (Teucrium stocksianum) } \\
\cline { 2 - 6 } & \multicolumn{5}{c|}{ Diameter (mm) } \\
Primary & Control & $0.03 \%$ Conc. & $0.05 \%$ Conc. & $0.1 \%$ Conc. & $0.5 \%$ Conc. \\
Secondary & 1.0 & 0.7 & 0.6 & 0.5 & 0.4 \\
Tertiary & 0.8 & 0.6 & 0.4 & 0.5 & 0.5 \\
\end{tabular}




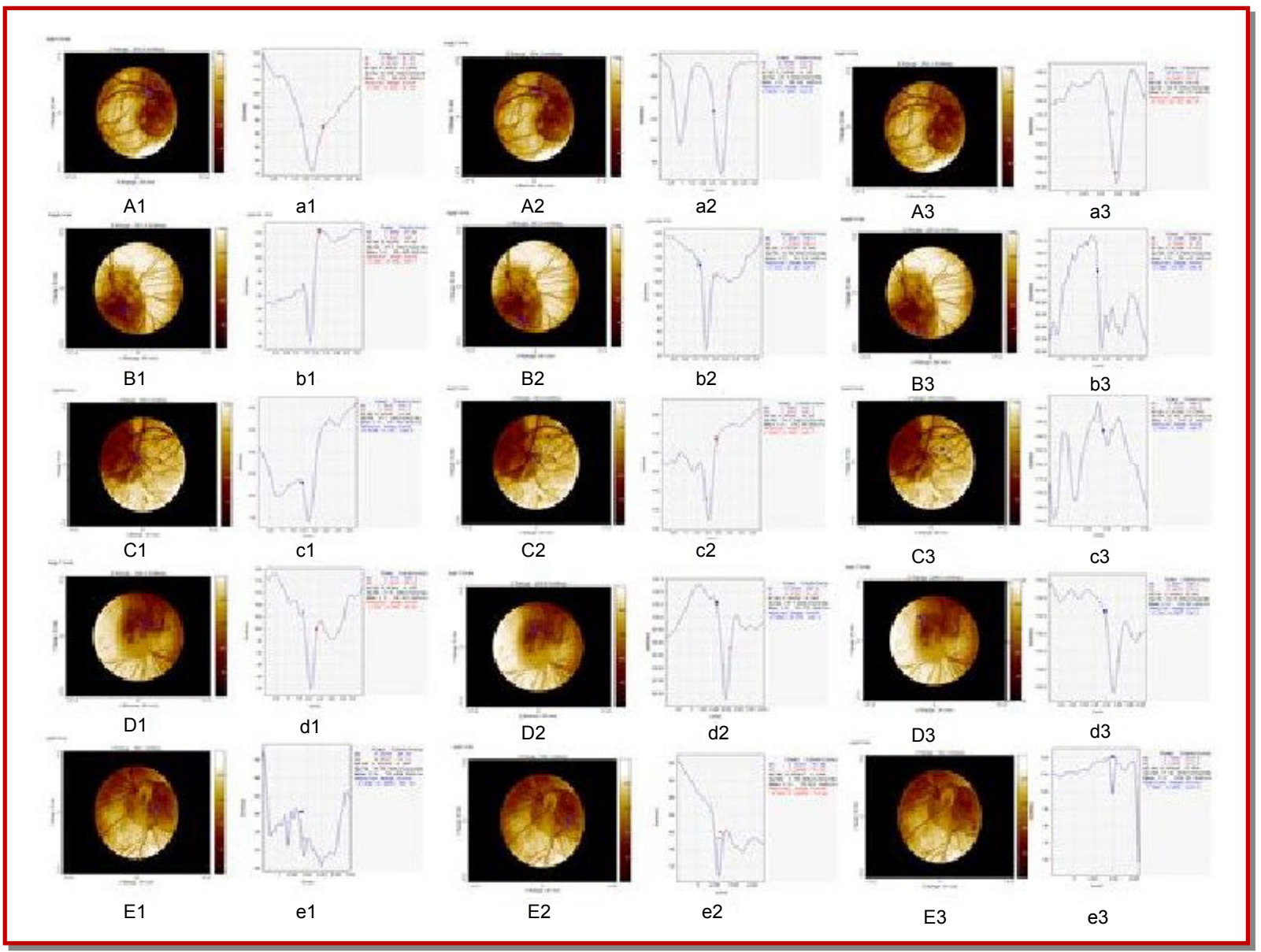

Figure 2: SPIP generated branching pattern and quantification of primary, secondary and tertiary blood vessels $1=$ Primary blood vessel (PBVs), 2= Secondary blood vessel (SBVs), 3= Tertiary blood vessel (TBVs); $\mathrm{A}=$ Control, $\mathrm{B}=0.03 \%$ treated T. stocksianum, $\mathrm{C}=0.05 \%$ treated $\mathrm{T}$. stocksianum, $\mathrm{D}=0.1 \%$ treated $\mathrm{T}$. stocksianum, $\mathrm{E}=0.5 \%$ treated $\mathrm{T}$. stocksianum, $\mathrm{a}-\mathrm{e}=\mathrm{quantifica-}$ tion of blood vessels in term of diameter of above mentioned control, standard and test samples

\begin{tabular}{|c|c|c|c|c|c|}
\hline \multicolumn{6}{|c|}{ Table II } \\
\hline \multicolumn{6}{|c|}{ Control and treated CAMs roughness parameters (T. stocksianum) } \\
\hline \multirow[t]{2}{*}{ Parameters } & \multirow[t]{2}{*}{ Control } & \multicolumn{4}{|c|}{ Concentration of extract } \\
\hline & & $0.03 \%$ & $0.05 \%$ & $0.1 \%$ & $0.5 \%$ \\
\hline Average roughness & $81.1 \pm 1$ & $72.3 \pm 2.2^{*}$ & $67.8 \pm 2.0^{*}$ & $49.2 \pm 2.5^{*}$ & $57.0 \pm 9.1^{*}$ \\
\hline Root mean square deviation & $86.1 \pm 3$ & $71.1 \pm 4.0^{*}$ & $71.5 \pm 1.6^{*}$ & $56.7 \pm 3.0^{*}$ & $64.8 \pm 10.2^{*}$ \\
\hline Skewness of the surface & $1.0 \pm 0.0$ & $0.5 \pm 0.2^{*}$ & $0.9 \pm 0.1$ & $0.1 \pm 0.0^{*}$ & $0.8 \pm 0.1$ \\
\hline Kurtosis of the surface & $2.3 \pm 0.0$ & $3.3 \pm 0.1^{*}$ & $3.1 \pm 0.1^{*}$ & $3.6 \pm 0.1^{*}$ & $3.7 \pm 0.6$ \\
\hline Lowest valley & $282.4 \pm 2.2$ & $263.9 \pm 7.2^{*}$ & $261.0 \pm 1^{*}$ & $231.0 \pm 1.6^{*}$ & $225.0 \pm 10.1^{*}$ \\
\hline Maximum height of the surface & $282.4 \pm 2.2$ & $263.9 \pm 7.2^{*}$ & $261.08 \pm 1^{*}$ & $231.0 \pm 1.5^{*}$ & $225.04 \pm 10.1^{*}$ \\
\hline Arithmetic mean summit & $1.9 \pm 1.1$ & $1.0 \pm 2.6^{*}$ & $1.0 \pm 6.0^{*}$ & $1.1 \pm 6.4^{*}$ & $1.3 \pm 2.0^{*}$ \\
\hline Root mean square slope & $0.1 \pm 7.6$ & $0.1 \pm 1.3^{*}$ & $0.1 \pm 5.1^{*}$ & $9.3 \pm 6.4^{*}$ & $8.7 \pm 6.6^{*}$ \\
\hline Developed surface area ratio & $7.0 \pm 9.2$ & $5.7 \pm 5.6^{*}$ & $1 . \pm 8.5^{*}$ & $4.2 \pm 5.2$ & $5.5 \pm 1$ \\
\hline Core fluid retention & $1.9 \pm 0.1$ & $1.2 \pm 0.1^{*}$ & $1.2 \pm 0.1^{*}$ & $1.1 \pm 0.1^{*}$ & $1.6 \pm 0.5$ \\
\hline Reduce summit height & $266.1 \pm 1.2$ & $249.1 \pm 3.1^{*}$ & $248.1 \pm 1.5^{*}$ & $160.3 \pm 1^{*}$ & $174.2 \pm 6.0^{*}$ \\
\hline Texture index & $0.8 \pm 0.1$ & $0.3 \pm 0.1^{*}$ & $0.5 \pm 0.1^{*}$ & $0.5 \pm 0.1^{*}$ & $0.5 \pm 0.1^{*}$ \\
\hline Core roughness depth & $42.6 \pm 1.6$ & $29.6 \pm 2.0^{*}$ & $30.2 \pm 5^{*}$ & $32.0 \pm 3.0^{*}$ & $32.5 \pm 1.1^{*}$ \\
\hline Reduce valley depth & $1.8 \pm 0.1$ & $1.3 \pm 0.1^{*}$ & $1.2 \pm 0.1^{*}$ & $1.3 \pm 0.1^{*}$ & $1.0 \pm 0.1^{*}$ \\
\hline
\end{tabular}

'E' Stand for Exponent; " *,'Significance $(\mathrm{p}<0.05)$; “",Highly significance $(\mathrm{p}<0.01)$ 


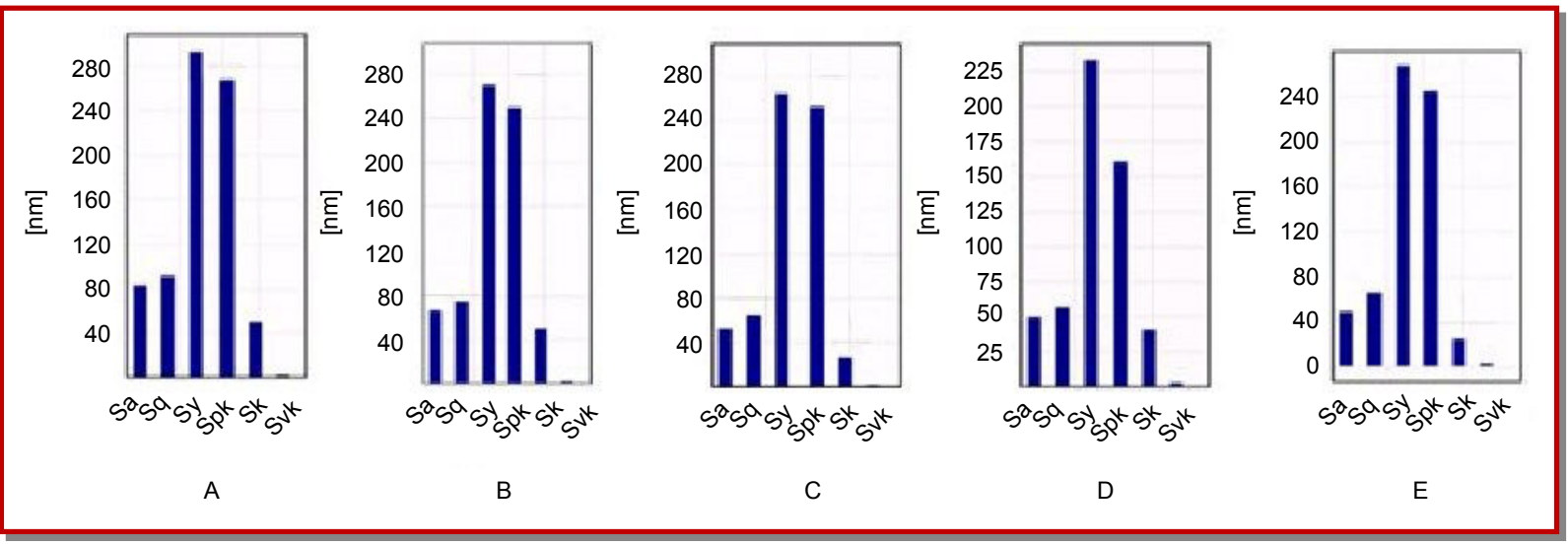

Figure 3: The graphical representation of various surface roughness parameters A) Control CAM B) $0.03 \%$, C) $0.05 \%$ D) $0.1 \%$ E) $0.5 \%$ treated Teucrium stocksianum CAMs

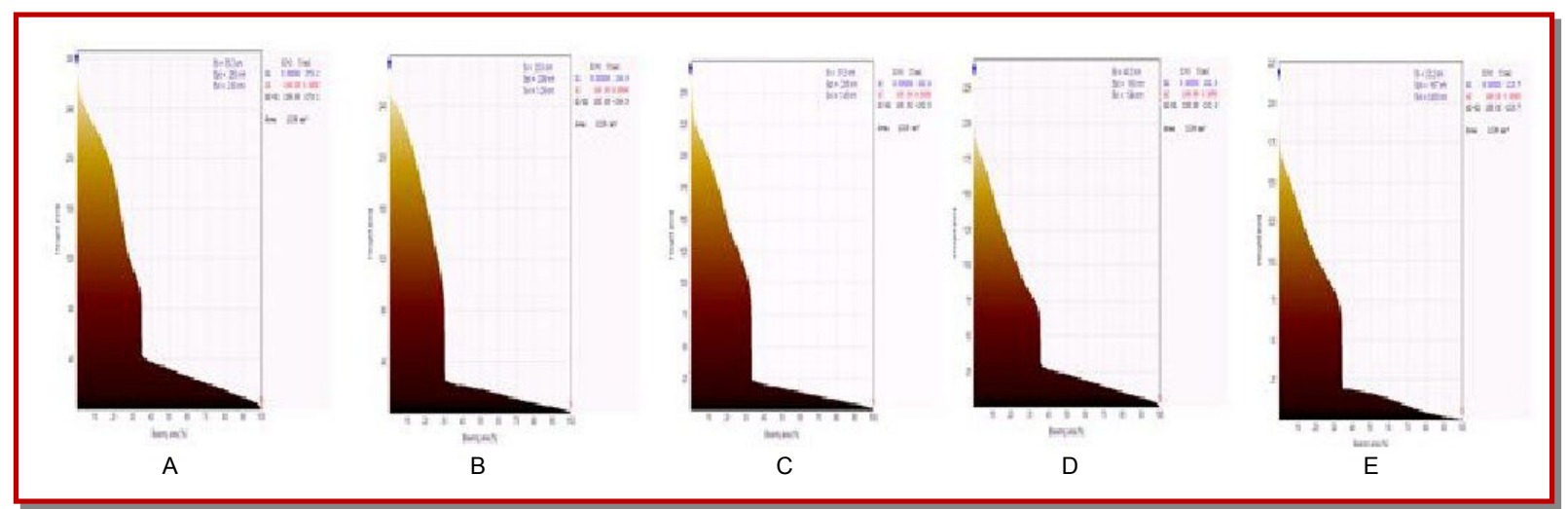

Figure 4: Abbott curve of CAM blood vessels A) Control CAM, B) $0.03 \%$, C) $0.05 \%$ D) $0.1 \%$ E) $0.5 \%$ treated T. stocksianum CAMs

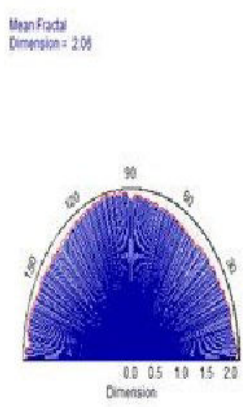

A

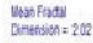

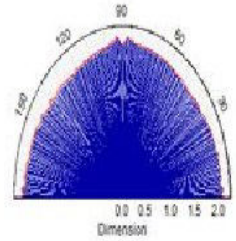

A

$$
\text { Wyan frat }
$$

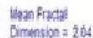

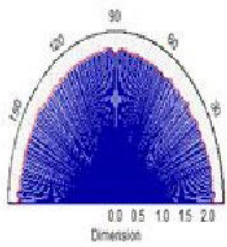

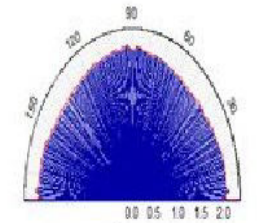

thankisut

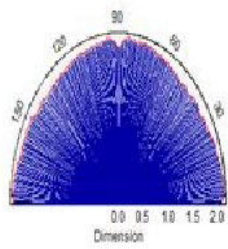

B

Figure 5: Angular spectrum of CAMs A) Control CAM, B) $0.03 \%$ C) $0.05 \%$ D) $0.1 \%$ E) $0.5 \%$ treated Teucrium stocksianum CAM

summit height, texture index, reduced valley depth, and core roughness depth were less the treated CAMs as compared to control CAMs.

The result showed that values of $3 \mathrm{D}$ roughness parameters of $T$. stocksianum were decreased than control (Figure 3). Moreover, graphical representation by abbott curve and angular spectrum showed that in T. stocksianum height of abbott curve (Figure 4) and angular spectrum (Figure 5) was decreased than in control.

Similarly, control CAMs angular spectrum and treated
CAMs angular spectrum were measured. The angular spectrum refers to amplitude of regular intensity variation with angle. The result showed that height of curve for control CAM in Abbott curve and angular spectrum was increased in comparison with values of height of curve with T. stocksianum.

\section{Discussion}

CAM area and average surface roughness parameters were quantified to determine the anti-angiogenic 
activity of T. stocksianum extract. There was found decrease in CAM area, diameter of blood vessels, height of abbott curve and average surface roughness of all treated groups as compared to control group values. Statistically significant $(\mathrm{p}<0.05)$ reduction in blood vessels diameter was found at $0.5 \%$ treated group. Extent of angiogenesis and CAM area has direct relationship i.e. increase in angiogenesis increases the CAM area and vice versa (Ejaz et al., 2005).

Number of studies showed that plants rich in flavonoids and saponins possessed anti-angiogenic activity by inhibiting the vascular endothelial growth factor (VEGF), bFGF-induced endothelial cell growth and migration e.g. Euphorbia helioscopia (Aduragbenro et al., 2009; Story et al., 2009).

CAM is the highly vascularized area and vascularization is due to angiogenesis. The compounds showing anti-angiogenic activity reduce the CAM area, diameter of blood vessels and average surface roughness of CAM. Decrease in CAM area, blood vessels diameter and average surface roughness of CAM in this study are an indicative parameters of antiangiogenic property of T. stocksianum.

\section{Conclusion}

T. stocksianum possessed anti-angiogenic activity that was attributed to the presence of high constituents of flavonoids and saponins in the plant. This could be employed as an adjuvant therapy with other antineoplastic drugs to inhibit tumor growth and metastasis.

\section{References}

Aduragbenro DAA, Yeside OO, Adeolu AA, Olanrewaju MJ, Ayotunde SA, Olumayojun AO, Janet MM. Blood pressure lowering effect of Adenanthera pavonina seed extract on normotensive rats. Rec Nat Prod. 2009; 3: 82.

Alamgeer, Rashid M, Bashir, S, Mushtaq MN, Khan H, Malik MNH, Qayyum A, Rahaman MS. Comparative hypoglycemic activity of differentextracts of Teucrium stocksianum in diabetic rabbits. Bangladesh J Pharmacol. 2013; 8: 186-93.

Ali N, Shah SWA. Antispasmodic activity of Teucrium stocksianum boiss. Antispasmodic activity of Teucrium stocksianum Boiss. Pakistan J Pharm Sci. 2011; 24: 171-74.

Ali N, Shah SWA, Shah I, Ahmed G, Ghias M, Khan I. Cytotoxic and anthelmintic potential of crude saponins isolated from Achillea wilhelmsii, C. Koch and Teucrium stocksianum Boiss. BMC Complement Altern Med. 2011; 11: 106.

Auerbach R, Rachel L, Brenda S, Louis K, Nasim A. Angiogenesis assays: A critical overview. Clin Chem. 2003; 49: 132 -40 .

Barkatullah, Ibrar M, Hussain F. Ethnobotanical studies of plants of Charkotli Hills, Batkhela District, Malakand,
Pakistan. Front Biol China. 2009; 4: 539-48.

Bouloumie A, Valerie B, SchiniK, Rudi B. Vascular endothelial growth factor up-regulates nitric oxide synthase expression in edothelail cells. Cardiovasc Res. 1999; 41: 773-80.

Brown NS, Jones A, Fujiyama C, Harris AL, Bicknell R. Thymidine phosphorylase induces carcinoma cell oxidative stress and promotes secretion of angiogenic factors. Cancer Res. 2000; 60: 6298-302.

Ejaz S, Seok KB, Woong LC. Toxicological effects of mainstream whole smoke solutions on embryonic movements of the developing embryo. Drug Chem Toxicol. 2005; 28: 1-14.

Folkman J. Tumor angiogenesis: Therapeutic implications. New Engl J Med. 1971 285: 1182-86

Ferrara N, Davis-Smyth T. The biology of endothelial growth factor. Endocr Rev. 1997; 18: 4-25

Garnaes J, Hansen PE, Agersnap N, Holm J, Borsetto F, Kuhle A. Profiles of a high aspect ratio grating determined by spectroscopic and atomic-force microscopy. Appl Opt. 2006; 45: 3201-12.

Islam MW, Zakaria MNM, Radhakrishnan R, Kamil M. Effect of Teucrium stocksianum on gastric ulceration and secretion in rats. Pharmaceut Biol. 2002; 40: 216-20.

Lin JY, Tang CY. Strawberry, loquat, mulberry and bitter melon juices exhibit prophylactic effects on LPS-induced inflammation using murine peritoneal macrophages. Food Chem. 2008; 107: 1587-96.

Mojab F, Javidnia K, Yazdani D, Rustaiynan A. Essential oil of the aerial parts of Teucrium stocksianum Boiss subsp. Stocksianum (Lamiacea) from Iran. J Med Plants. 2003; 2: 4953.

Miller GA, Morris M. Ethnoflora of the Socotra Archipelago. Charlesworth Group, Huddersfield, UK, 2004, pp 457-64.

Naghibi F, Mosaddegh M, Motamed MS, Ghorbani A. Labiatae family in folk medicine in Iran from ethnobotany to pharmacology. IJPR. 2005; 2: 63-79.

Nadaf SK, Al-Farsi SM, Al-Hinai SA. Germplasm collection of range land forage and medicinal plant species in north Oman. In: Annu Rep ICARDA-APRP. ICARDA-APRP, Dubai, 2003, pp 63-64.

Pepper MS. Manipulating angiogenesis: From basic sciences to besides. Arterioscler Thromb Vasc Biol. 1997; 17: 605-19.

Shah SMM, Sadiq A, Shah SMH, Ullah F. Antioxidant, total phenolic contents and antinociceptive potential of Teucrium stocksianumm ethanolic extract in different animal models. BMC Complement Altern Med. 2014; 14: 181.

Story M, Nanney MS, Schwartz MB. Schools and obesity prevention: Creating school environments and policies to promote healthy eating and physical activity. PMCID 2009; 87: 71-100.

Western AR. The flora of the United Arab Emirates, an introduction. United Arab Emirates University. Al-Ain, U.A.E., 1989.

Author Info
Abdul Aziz (Principal contact)




\section{Your feedback about this paper}

1. Number of times you have read this paper 0

2. Quality of paper Click

3. Your comments

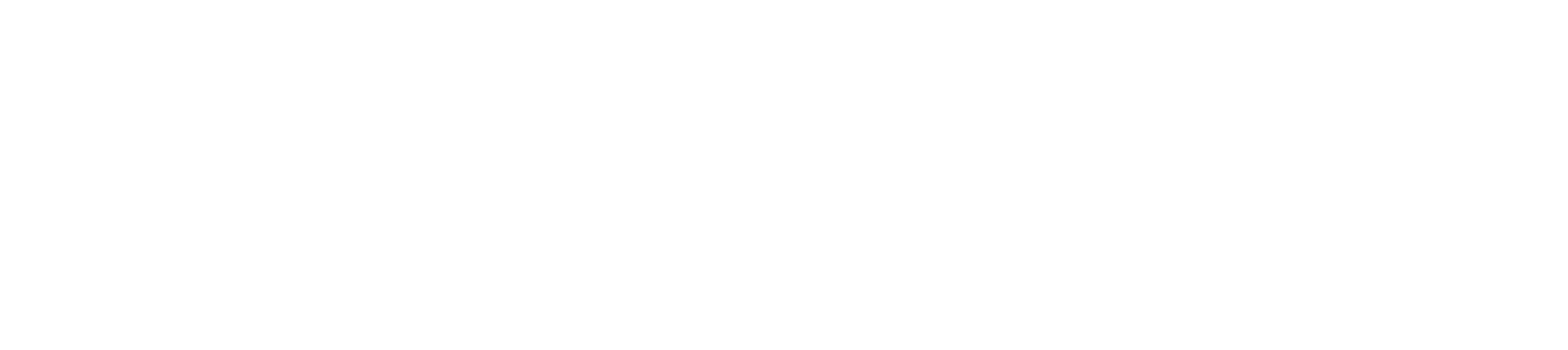

